\title{
Linear Viscoelasticity of Textured Carbonaceous Mesophases
}

\author{
Luiz Rogério P. de Andrade Lima ${ }^{*, a}$ and Alejandro D. Rey \\ ${ }^{a}$ Departamento de Ciência e Tecnologia dos Materiais, Universidade Federal da Bahia CP 6974, \\ 41810-971 Salvador-BA, Brazil \\ ${ }^{b}$ Department of Chemical Engineering McGill University 3610 University Street, Montreal, Canada, H3A 2B2
}

Fibras de carbono de alto desempenho podem ser produzidas a partir de piche de petróleo anisotrópico usando o processo de extrusão-fiação. O piche mesomórfico é um cristal líquido discótico nemático termotrópico, que possui ordem na orientação das moléculas. Cristais líquidos são materiais que possuem textura, anisotropia e visco-elasticidade. Um fenômeno importante que é encontrado em cristais líquidos é a interação entre a textura devido à orientação das moléculas e o comportamento reológico, no qual a textura ocorre devido à presença de defeitos na orientação das moléculas. O processo de extrusão-fiação usado na fabricação de fibras de carbono a partir de precursores nemáticos usa uma cascata de escoamentos que incluem fluxo capilar convergente e extensional, os quais promovem a formação de uma variedade de estruturas, incluindo radial, concêntrica, randômica e bipolar, que darão propriedades especificas para as fibras de carbono resultantes. Portanto, a compreensão fenomenológica da interação entre a textura e a reologia do precursor nemático é necessária para o controle do processo e para a otimização do produto. Neste artigo, a interação entre a reologia e a textura de cristais líquidos discóticos nemáticos será enfocada e um modelo anisotrópico será desenvolvido para descrever o regime linear visco-elástico de piches mesofásico com textura. O modelo é capaz de prever todas as características observadas experimentalmente, incluindo a dependência dos módulos de armazenamento e de perda com a freqüência de oscilação e a sua dependência com a temperatura, assim como promover uma melhor compreensão do papel dos defeitos e da anisotropia no comportamento visco-elástico do piche anisotrópico.

High performance carbon fibers can be produced from anisotropic petroleum pitch using the fiber spinning process. The mesophase pitch is a thermotropic discotic nematic liquid crystal possessing orientational order. Liquid crystals are textured, anisotropic, viscoleastic materials. An important phenomenon of liquid crystals is the interaction between orientational textures and rheology, where the texture is due to the presence of orientational defects. The fiber spinning process used in the carbon fiber manufacture from nematic precursors uses a cascade of processing flows that involves capillary, convergent, and extensional flows, which promotes the formation of a variety of textures that will give specific properties to the resultant carbon fiber. Hence a fundamental understanding of the impact of textures on rheology is needed for eventual process control and product optimization. In this paper we study the interaction of rheology and texture and develop a model of anisotropic linear viscoelasticity of textured mesophases. The model is able to predict all the features observed experimentally, including the frequency dependency of the loss and storage modulus and their temperature sensitivity, and provides a better understanding of the role of defects and anisotropy on pitch viscoelasticity.

Keywords: mesophase pitch, rheology, nematic discotic liquid crystal, carbon fiber, LeslieEricksen theory, texture, anisotropy

\section{Introduction}

High performance carbon fibers can be produced from liquid crystalline petroleum pitches, also known as carbonaceous mesophase, using the melt spinning

*e-mail: lelo@ufba.br process, which was introduced in the 1970s to produce carbon fibers with ultra-high modulus and very high thermal and electrical conductivities. The melt spinning process consists of a flow sequence that induces unique textural transformations in the mesophase. ${ }^{1-4}$ Improvements in the high performance carbon fiber quality require a better understanding of the interaction 


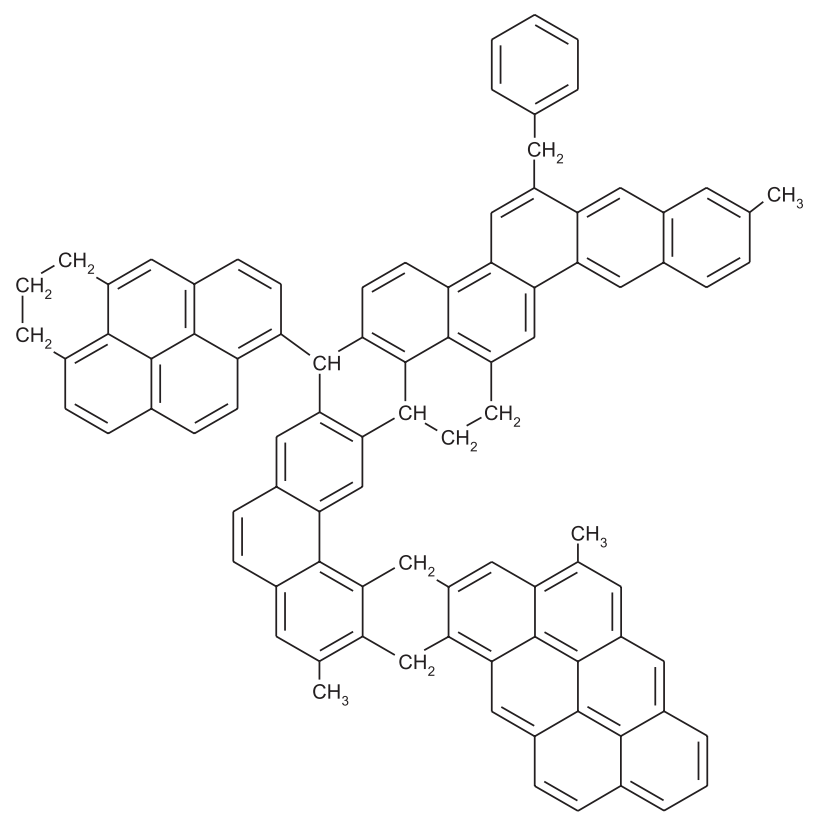

(a)

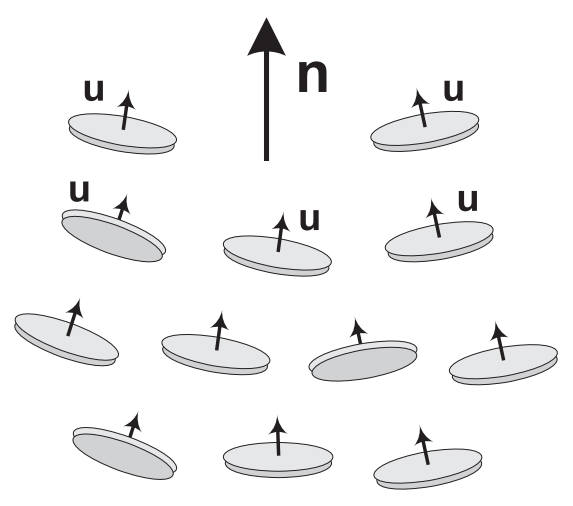

(b)

Figure 1. a) Typical disk-like molecule found in mesophase pitch (Adapted from references 2, 3, 4). (b) Definition of the director orientation of a uniaxial discotic nematic liquid crystalline material; the director vector $\mathbf{n}$ is the average orientation of the unit normal vector $\mathbf{u}$ to the disklike molecules.

between the rheology and texture of carbonaceous mesophase precursors.

Carbonaceous mesophases are textured anisotropic viscoelastic materials formed by flat aromatic molecules, see Figure 1a for a representative molecule. ${ }^{1-4}$ This material exhibits orientational order and positional disorder and is a discotic nematic thermotropic liquid crystal. ${ }^{5,6}$ The description of complex fluids systems such as discotic nematic liquid crystals by molecular dynamic or other microscopic approach is a complex task due to difficulties of computational implementation and the correct definition of the interaction potentials. A convenient and widely used approach to describe anisotropic liquids employs the average description of the molecular orientation. The theory most widely used to describe liquid crystalline system is that of EricksenLeslie, in which mass and linear momentum balance are coupled to angular momentum balance..$^{5-7}$ The latter is basically a torque balance in which viscous torques are balanced by elastic torques. The torque balance equation describes the spatio-temporal evolution of the average molecular orientation under the action of externally imposed flow fields. Figure $1 \mathrm{~b}$ shows a schematic of the discotic nematic liquid crystalline phase, where the unit normals to the discs-like molecules (u) orient more or less parallel to the average molecular orientation, known as the director $\mathbf{n}$, which is a unit vector: $\mathbf{n} . \mathbf{n}=1$.

Since discotic mesophases have orientational order, the average molecular orientation is affected by external flow, a mechanism known as flow-induced orientation. ${ }^{5-7}$ These materials are also elastic, such that spatial gradients of the average molecular orientation increases the energy. The three basic elastic storage modes for discotic nematics are splay, twist, and bend, and are shown in Figure 2.5-7 Therefore, any imposed processing flow creates through the balance between flow-induced orientation and elastic torques a unique texture that is defined by spatial characteristics of the director field such as orientation gradients, boundary layers, topological defects, and defect networks. The characterization and identification of liquid crystallinity is evaluated by polarized optical microscopy, since different textures correspond to different optical outputs. $^{1-4}$

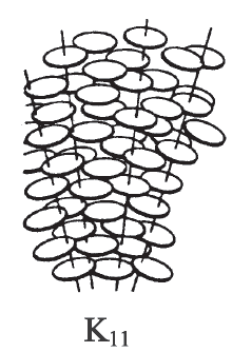

(a)

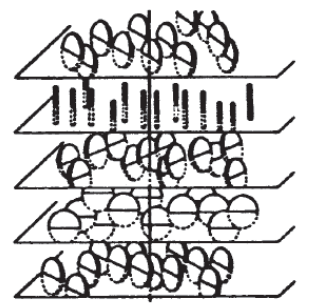

$\mathrm{K}_{22}$

(b)

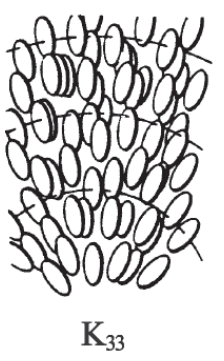

(c)
Figure 2. Schematics of the elastic splay, twist, and bend distortion modes for uniaxial discotic nematics, and the associated elastic constants, $\mathrm{K}_{11}$, $\mathrm{K}_{22}$ and $\mathrm{K}_{33}$, respectively.

Due to the practical importance of rheology in the fiber spinning process, and the eventual cost reduction, the experimental characterization of isotropic and mesophase pitches using steady and transient simple shear and Poiseuille flows has received some attention since the $1980 \mathrm{~s}^{8-17}$ The theoretical analyses of the experimental data, using constitutive equations appropriate to liquid 
crystalline systems, has received much less attention despite the fact that it is crucial to characterize the behavior of this complex material. ${ }^{18-23}$

Small amplitude oscillatory shear flow is a main rheological tool used to characterize the viscoelaticity in terms of storage modulus (G'), loss (G") modulus, and loss angle $(\delta)$ as a function of frequency $(\omega)$. The characterization of isotropic and mesophase pitches using this technique has recently received some attention. ${ }^{24-30}$ The main features of the experimental measurements in textured carbonaceous mesophase are summarized in Figure 3, which shows schematics of the master curves for the frequency dependence of the storage G' and loss G" linear viscoelastic moduli using the Williams-Landel-Ferry (WLF) superposition. ${ }^{11,25-27}$ Figure 4 shows an schematic of a 2D view of a textured carbonaceous mesophases displaying the polydomain state ${ }^{7} \mathrm{H}$ is the average domain size within which a more or less uniform $\mathbf{n}$ is found. The key observations that can be extracted from experimental data (for the reduced frequency less than $100(\mathrm{rad} / \mathrm{sec})$ ) are: (i) The

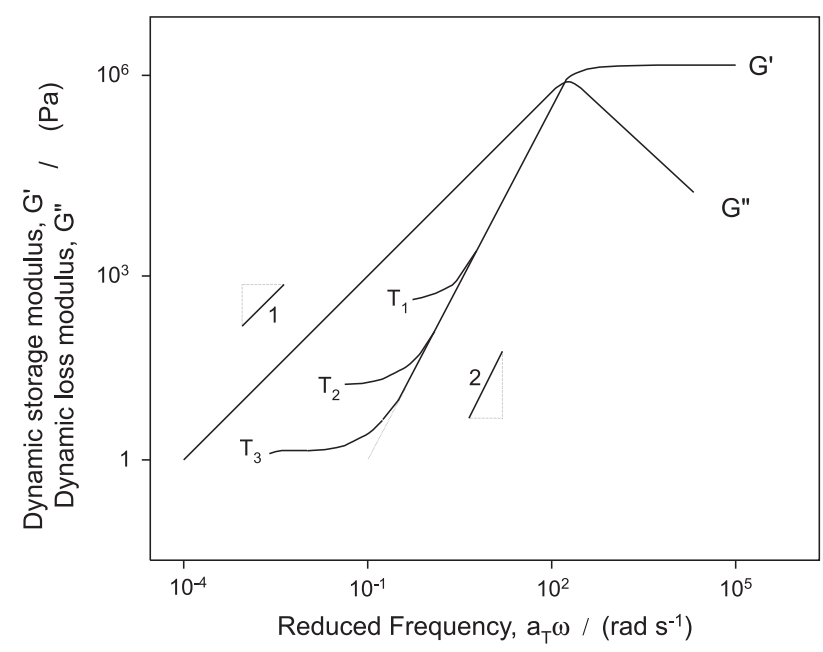

Figure 3. Schematics showing the general features of the master curves for dynamic storage and loss moduli versus reduced frequency for mesophase pitch at three temperatures $\left(\mathrm{T}_{1}<\mathrm{T}_{2}<\mathrm{T}_{3}\right)$ (Adapted from references $24,25,26,27$ )

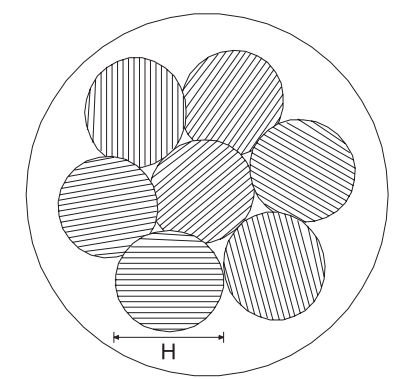

Figure 4. Schematics of a polydomain texture showing regions with different orientation of average size $\mathrm{H}$. loss modulus scales with G" $\omega$ and is independent of temperature; (ii) the storage modulus has a temperaturesensitive terminal zone (small $\omega$ ) exhibiting solid-like behavior followed by a temperature insensitive viscoelastic, where $\mathrm{G}^{\prime} \sim \omega^{2}$.

The experimental results can be summarized as follows: ${ }^{24-27} \mathrm{G}^{\prime \prime}=\mathrm{G}^{\prime \prime}(\omega,\langle\mathbf{n}\rangle), \mathrm{G}^{\prime}=\mathrm{G}^{\prime}(\omega, \mathrm{T},\langle\mathbf{n}\rangle, \mathrm{H})$, where $\langle\mathbf{n}\rangle$ is an average orientation that reflects splay, twist, and bend deformation modes.

Previous theoretical work ${ }^{31}$ on linear viscoelasticty was able to predict the frequency scalings $\left(\mathrm{G}^{\prime} \sim \omega^{2}, \mathrm{G}^{\prime} \sim \omega\right)$ using a single mode (i.e. pure splay) anisotropic model. In this paper we present a generalized model that takes into account splay and bend distortions, and include the role of defects and textures, thus explaining the solidlike behavior in the terminal zone, as shown in the experiments. ${ }^{24-27}$ Hence in this paper we present a mesoscopic model that includes the required information of director orientation $\langle\mathbf{n}\rangle$ and texture length scale $\mathrm{H}$ on the linear viscoelastic moduli. It should be mentioned that twist distortions have contribution to G' and their contribution to G" has the same frequency dependency as splay and bend. ${ }^{31}$ Hence there is no need to include the twist mode.

This paper is organized as follows: Section 2 presents the governing equations used to describe liquid crystalline system. The section 3 presents the results of the linear viscoelasticity for anisotropic textured carbonaceous mesophase. Section 4 presents the conclusions.

\section{Methods}

\section{Governing equations}

The continuum theory of elasticity of liquid crystals takes into account external forces and torques that introduce deformations in the relative molecular orientations and can distort the equilibrium configurations of the molecules. The elastic free energy density, $F_{d}$ a nematic uniaxial liquid crystal material is given by: ${ }^{5-7}$

$\mathrm{F}_{\mathrm{d}}=\frac{\mathrm{K}_{11}}{2}(\nabla \cdot \mathbf{n})^{2}+\frac{\mathrm{K}_{22}}{2}(\mathbf{n} \cdot \nabla \times \mathbf{n})^{2}+\frac{\mathrm{K}_{33}}{2}|\mathbf{n} \times \nabla \times \mathbf{n}|^{2}$

where the three basic modes of elastic storage are the splay $\left(\mathrm{K}_{11}\right)$, twist $\left(\mathrm{K}_{22}\right)$ and bend $\left(\mathrm{K}_{33}\right)$ modes, as mentioned above (see Figure 2).

The continuum theory of uniaxial nematic liquids consists of the linear and angular momentum balances, and 
constitutive equations for the stresses, viscous and elastic torques that takes into account external forces distort the spatially uniform equilibrium configurations of liquid crystals molecules. For incompressible isothermal conditions the general conservation of linear and angular momentum are given by the follows equations: ${ }^{5-7}$

$$
\begin{aligned}
& \rho\left(\frac{\partial \mathbf{v}}{\partial \mathrm{t}}+\mathbf{v} \cdot \nabla \mathbf{v}\right)=\mathbf{f}+\nabla \cdot \boldsymbol{\sigma} \\
& \rho_{1} \ddot{\mathbf{n}}=\mathbf{G}+\mathbf{g}+\nabla \cdot \boldsymbol{\pi}
\end{aligned}
$$

where $\rho$ is the density, $\mathbf{v}$ is the velocity vector, $\mathbf{f}$ is the body force per unit volume vector, $\boldsymbol{\sigma}$ is the total stress, $\rho_{1}$ is the moment of inertia per unit volume, $\mathbf{G}$ is the external director body force vector, $\mathbf{g}$ is the intrinsic director body force vector, and $\pi$ is the director stress tensor. The following constitutive equations for the stress tensor and the director body force that describes anisotropic liquids was found using transversely isotropic tensor coefficients, which reflect the material symmetry: $:^{5-7}$

$$
\begin{aligned}
& \boldsymbol{\sigma}=-\mathrm{p} \mathbf{I}-\frac{\partial \mathrm{F}_{\mathrm{d}}}{\partial \nabla \mathbf{n}} \cdot \nabla \mathbf{n}^{\mathrm{T}}+\alpha_{1}(\mathbf{n n}: \mathbf{A}) \mathbf{n n}+\alpha_{2} \mathbf{n N}+ \\
& \alpha_{3} \mathbf{N} \mathbf{n}+\alpha_{4} \mathbf{A}+\alpha_{5} \mathbf{n n} \cdot \mathbf{A}+\alpha_{6} \mathbf{A} \cdot \mathbf{n n} \\
& \mathbf{g}=\mathbf{a} \mathbf{n}-\boldsymbol{\beta} \cdot \nabla \mathbf{n}-\frac{\partial \mathrm{F}_{\mathrm{d}}}{\partial \mathbf{n}}-\gamma_{1} \mathbf{N}-\gamma_{2} \mathbf{n} \cdot \mathbf{A} \\
& \boldsymbol{\pi}=\boldsymbol{\beta} \mathbf{n}+\frac{\partial \mathrm{F}_{\mathrm{d}}}{\partial \nabla \mathbf{n}}
\end{aligned}
$$

where,

$$
\begin{aligned}
& \mathrm{A}=\left(\nabla \mathbf{v}+\nabla \mathbf{v}^{\mathrm{T}}\right) / 2 ; \quad \mathbf{W}=\left(\nabla \mathbf{v}-\nabla \mathbf{v}^{\mathrm{T}}\right) / 2 ; \quad \mathbf{N}=\dot{\mathbf{n}}-\mathbf{W} \cdot \mathbf{n} \quad(7 \mathrm{a}, \mathrm{b}, \mathrm{c}) \\
& \gamma_{1}=\alpha_{3}-\alpha_{2} ; \quad \gamma_{2}=\alpha_{6}-\alpha_{5}=\alpha_{3}+\alpha_{2} ; \quad \lambda=-\gamma_{2} / \gamma_{1}(8 \mathrm{a}, \mathrm{b}, \mathrm{c})
\end{aligned}
$$

$\mathrm{p}$ is the pressure, $\mathbf{I}$ is the unit tensor, $\left\{\alpha_{i}: \mathrm{i}=1,2,3,4,5\right.$, and 6$\}$, are the Leslie viscosity coefficients that describes an anisotropic liquid, $\mathbf{A}$ is the rate of deformation tensor, $\mathbf{N}$ is the corotational derivative of the director vector, $\boldsymbol{\beta}$ is an arbitrary vector, "a" is an arbitrary scalar used to constrain the director (n) to be a unit vector, $F_{d}$ is the elastic free energy density known as Frank elasticity, $\gamma_{1}$ is the rotational viscosity, $\gamma_{2}$ is the irrotational torque coefficient, $\mathbf{W}$ is the vorticity tensor, and $\lambda$ is the reactive parameter.

Experiments show that the average molecular orientation of mesophase pitch on solid surfaces can be either planar (edge-on) or homeotropic (face-on) depending of the nature of the substrate. ${ }^{32,33}$ The edge-on anchoring (see Figure 5) is the more frequently found, and is the result of strong non-covalent interactions involving aromatic $\pi$ clouds. ${ }^{32,33}$ In the analytical equations derived in our previous studies to describe the orientation field in capillary flow the average molecular orientation at the boundaries are assumed to be planar, and this also will be the case in this study. ${ }^{20,31,34-36}$

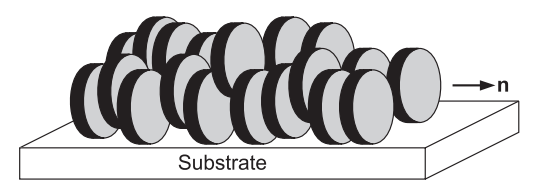

Figure 5. Schematics representation of planar (edge-on) surface anchoring of disc-like molecules on a substrate (Adapted from references 32, 33).

A detailed discussion about the viscoelastic properties involved in the small amplitude oscillatory shear of discotic nematics can be found in our previous papers, ${ }^{20,31,34-36}$ here we briefly present the essential features of the material properties. The main properties include: (i) the Frank elastic moduli with the three distortion modes, splay $\left(\mathrm{K}_{11}\right)$, twist $\left(\mathrm{K}_{22}\right)$, and bend $\left(\mathrm{K}_{33}\right)$ (see equation 1$)$; (ii) the Miesowicz shear viscosities that characterize viscous anisotropy and are measured in a steady simple shear flow between parallel plates with fixed director orientations along three characteristic orthogonal directions $\left(\eta_{1}\right.$ : when the director is parallel to the velocity direction, $\eta_{2}$ : when it is parallel to the velocity gradient, and $\eta_{3}$ : when it is parallel to the vorticity axis); (iii) the reactive parameter (see equation $8 \mathrm{c}$ ) and the flowalignment angle $\left(\theta_{\mathrm{s}}=1 / 2 \cos ^{-1}(1 / \lambda)\right)$ that obtains when $\lambda<-1$; (iv) the director re-orientation viscosities associated with splay, twist, and bend deformations $\left(\eta_{\text {tiwst }}=\gamma_{1}, \eta_{\text {splay }}=\gamma_{1}-\alpha_{3}^{2} / \eta_{1}\right.$, and $\left.\eta_{\text {bend }}=\gamma_{1}-\alpha_{2}^{2} / \eta_{2}\right)$, which are given by the rotational viscosity $\left(\gamma_{1}\right)$ decreased by a factor introduced by the backflow effect. ${ }^{7}$ Backflow is re-orientation driven flow and is essentially the reverse effect to flow-induced orientation. ${ }^{7}$ Note that twist is the only mode that creates no backflow. ${ }^{7}$

\section{Results and Discussion}

\section{Linear viscoelasticity of monodomain and polydomain carboanceous mesophase}

The solution of equations 1 to $8 \mathrm{c}$ for simple shear flow and capillary Poiseuille flow, assuming linear behavior that happens at small deformation regime as in the case of small amplitude oscillatory flows, allows the derivation of viscoelastic functions, namely the storage modulus ( $\left.\mathrm{G}^{\prime}\right)$, the loss modulus ( $\left.\mathrm{G}^{\prime \prime}\right)$, and loss tangent $\left(\tan \delta=\widetilde{\mathrm{G}}^{\prime} / \widetilde{\mathrm{G}}^{\prime}\right):^{31,34-36}$ 
$\widetilde{\mathrm{G}}^{\prime}(\widetilde{\omega}, \mathbf{n}, \mathrm{T})=\frac{\mathrm{P}_{1} \mathrm{U}_{2}(\widetilde{\omega})}{\mathrm{U}_{2}(\widetilde{\omega})^{2}+\left(\mathrm{P}_{2}-\mathrm{U}_{1}(\widetilde{\omega})\right)^{2}} \widetilde{\omega}$

$\widetilde{G}^{\prime \prime}(\widetilde{\omega}, \mathbf{n}, T)=\frac{P_{1}\left(P_{2}-U_{1}(\widetilde{\omega})\right)}{U_{2}(\widetilde{\omega})^{2}+\left(P_{2}-U_{1}(\widetilde{\omega})\right)^{2}} \widetilde{\omega}$

$\tan \delta(\widetilde{\omega}, \mathbf{n}, T)=\frac{P_{2}-U_{1}(\widetilde{\omega})}{U_{2}(\widetilde{\omega})}$

where $\mathrm{U}_{1}$ and $\mathrm{U}_{2}$ are frequency-dependent functions, and $\mathrm{P}_{1}$ and $\mathrm{P}_{2}$ are the material properties ratios that assume distinct values for the distinct distortion modes (i.e. splay, bend, and twist) as shown in Table 1. As mentioned above, the twist mode is not included because this mode does not contribute to elastic storage. Since the material parameters $\left\{\mathrm{P}_{1}(\mathrm{~T}, \mathbf{n}), \mathrm{P}_{2}(\mathrm{~T}, \mathbf{n})\right\}$ are functions of $(\mathrm{T}, \mathbf{n})$ (see Table 1$),{ }^{31,36}$ the linear viscoelastic functions (equations 9 to 11) are also functions of $(\mathrm{T}, \mathbf{n})$. In particular, when $\mathbf{n}$ is along the flow direction the distortion mode bend and when is along the shear rate direction, the distortion mode is pure splay.
In this paper the calculations are performed using a set of estimated viscoelastic material parameters listed in Table $2 .^{15,18}$ The characteristic size (L) is the gap between plates or the capillary radius in the rheometer. The essential features of the solutions and the main conclusions of this paper will remain unaffected if other parameters are used but the reactive parameter $(\lambda)$ is less than minus one and if the Miesowicz inequalities hold. ${ }^{20-23}$

Figures $6 a$ and $6 b$ shows the dynamic moduli ( $G$ " and $\left.G^{\prime}\right)$ and the phase lag as a function of the frequency $(\omega)$ for a single distortion mode (splay and bend, respectively) of a monodomain (defect free). In both splay and mode cases, the low frequency (terminal) regime is classic of a viscous fluid, and the loss modulus is always greater than the storage modulus. The characteristic slopes in both cases are:

$$
\begin{aligned}
& \widetilde{\omega} \rightarrow 0, \widetilde{\mathrm{G}}^{\prime} \sim \widetilde{\omega}^{2}, \widetilde{\mathrm{G}}^{\prime} \sim \widetilde{\omega} \\
& \widetilde{\omega} \rightarrow \infty, 0, \widetilde{\mathrm{G}}^{\prime} \sim \widetilde{\omega}^{1 / 2}, \widetilde{\mathrm{G}}^{\prime \prime} \sim \widetilde{\omega}
\end{aligned}
$$

\begin{tabular}{|c|c|c|}
\hline & Bend & Splay* \\
\hline \multirow[b]{2}{*}{$\widetilde{\omega}:$} & $\omega \eta_{\text {bend }} L^{2}$ & $\omega \eta_{\text {splay }} L^{2}$ \\
\hline & $\mathrm{K}_{33}$ & $\mathrm{~K}_{11}$ \\
\hline$\tilde{\mathrm{G}}^{\prime}:$ & $\mathrm{G}^{\prime} \mathrm{L}^{2} / \mathrm{K}_{33}$ & $\mathrm{G}^{\prime} \mathrm{L}^{2} / \mathrm{K}_{11}$ \\
\hline$\tilde{\mathrm{G}^{\prime}}:$ & $\mathrm{G}^{\prime \prime} \mathrm{L}^{2} / \mathrm{K}_{33}$ & $\mathrm{G}^{\prime \prime} \mathrm{L}^{2} / \mathrm{K}_{11}$ \\
\hline $\mathrm{P}_{1}:$ & $\left(\frac{\eta_{2}}{\alpha_{2}}\right)^{2}$ & $\left(\frac{\eta_{1}}{\alpha_{3}}\right)^{2}$ \\
\hline $\mathrm{P}_{2}:$ & $\frac{\eta_{2} \gamma_{1}}{\alpha_{2}^{2}}$ & $\frac{\eta_{1} \gamma_{1}}{\alpha_{3}^{2}}$ \\
\hline \multirow{3}{*}{$\mathrm{U}_{1}:$} & $\sinh \sqrt{\frac{\widetilde{\omega}}{2}}-\sin \sqrt{\frac{\widetilde{\omega}}{2}}$ & ber $_{1} \sqrt{\widetilde{\omega}}\left(\right.$ bei $_{0} \sqrt{\widetilde{\omega}}-$ ber $\left._{0} \sqrt{\widetilde{\omega}}\right)-$ bei $_{1} \sqrt{\widetilde{\omega}}\left(\right.$ ber $_{0} \sqrt{\widetilde{\omega}}+$ bei $\left._{0} \sqrt{\widetilde{\omega}}\right)$ \\
\hline & $\frac{1}{\sqrt{2 \widetilde{\omega}}} \frac{\sqrt{2} \cosh ^{2} \sqrt{\frac{\widetilde{\omega}}{8}}-\sin ^{2} \sqrt{\frac{\widetilde{\omega}}{8}}}{\sqrt{2}}$ & $-\frac{\sqrt{8 \widetilde{\omega}}}{8}\left(\mathrm{ber}_{1}{ }^{2} \sqrt{\widetilde{\omega}}+\mathrm{bei}_{1}{ }^{2} \sqrt{\widetilde{\omega}}\right)$ \\
\hline & $1 \sin \sqrt{\frac{\widetilde{\omega}}{2}}+\sinh \sqrt{\frac{\widetilde{\omega}}{2}}$ & bei $_{1} \sqrt{\widetilde{\omega}}\left(\right.$ ber $_{0} \sqrt{\widetilde{\omega}}-$ bei $\left._{0} \sqrt{\widetilde{\omega}}\right)-$ ber $_{1} \sqrt{\widetilde{\omega}}\left(\right.$ bei $_{0} \sqrt{\widetilde{\omega}}+$ ber $\left._{0} \sqrt{\widetilde{\omega}}\right)-8$ \\
\hline $\mathrm{U}_{2}$ : & $\overline{\sqrt{2 \widetilde{\omega}}} \cosh ^{2} \sqrt{\frac{\widetilde{\widetilde{\omega}}}{8}}-\sin ^{2} \sqrt{\frac{\widetilde{\omega}}{8}}$ & $\frac{\sqrt{8 \widetilde{\omega}}}{8}\left(\right.$ ber $_{1}^{2} \sqrt{\widetilde{\omega}}+$ bei $\left._{1}{ }^{2} \sqrt{\widetilde{\omega}}\right)$ \\
\hline
\end{tabular}

Table 1. Material properties, scaling, viscoelastic parameters, and frequency functions for bend and splay deformation modes ${ }^{31,35,36}$

* bei $_{v}(x)$ and $\operatorname{ber}_{v}(x)$ are the Kelvin functions of order $v .^{31,34-36}$ 

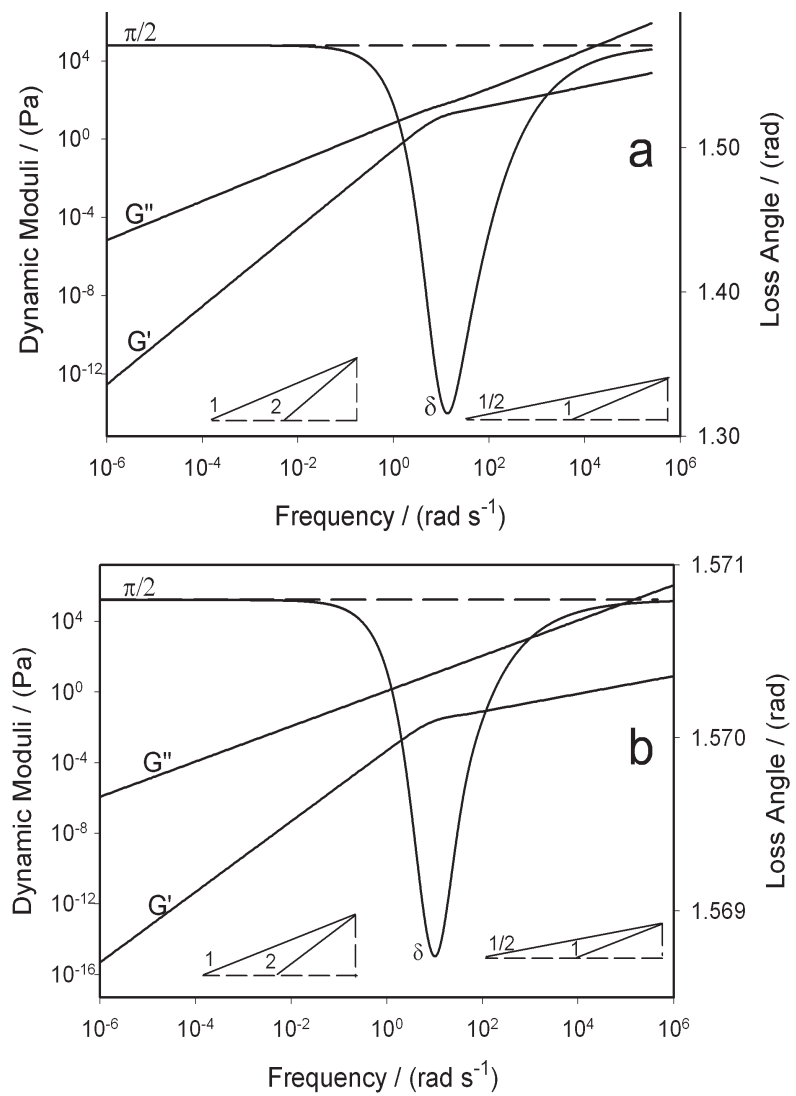

Figure 6. Computed storage modulus (G'), loss modulus (G'), and loss angle $(\delta)$ for mesophase pitch as a function of the frequency $(\omega)$ for single distortion mode and monodomain (adapted from references 31, 36). a) Splay distortion; b) Bend distortion.

Table 2. Assumed parametric values (references 15 and 18)

\begin{tabular}{ccc}
\hline \multicolumn{3}{c}{ Leslie viscosities coefficients $(\mathrm{Pa} \mathrm{s})$} \\
\hline$\alpha_{1}$ & 36.2890 \\
$\alpha_{2}$ & 0.4680 \\
$\alpha_{3}$ & 6.6500 \\
$\alpha_{4}$ & 20.2700 \\
$\alpha_{5}$ & -5.4000 \\
$\alpha_{6}$ & 1.7200 \\
\hline \multicolumn{3}{c}{ Frank elastic constants $\left(\times 10^{-8} \mathrm{~N}\right)$} \\
\hline $\mathrm{K}_{11}$ & 1.5 \\
$\mathrm{~K}_{33}$ & 1.0 \\
\hline \multicolumn{3}{c}{ Characteristic size $(\mathrm{m})$} \\
\hline $\mathrm{L}$
\end{tabular}

These single mode results capture features of the experimental data shown in Figure 3 but miss the temperature dependence of $\mathrm{G}^{\prime}$, as well as the solid-like terminal frequency plateau of G'. On the other hand, the single mode model reproduces the experimentally observed G" response. Since the slope of G" is insensitive to the deformation mode, there is no need to developed a multimode equation. Hence we conclude from the present theory (Figures 6a and 6b) and from experiments (Figure 3) that G" is insensitive to the distortion mode and to textural processes. Next we focus attention to $G^{\prime}$ and develop a model based on liquid crystal physics that reproduces the features of G' shown in Figure 3.

In this study the storage modulus $G$ ' of textured carbonaceous mesophase, with splay, and bend deformation domains is estimated using the aggregate model, which is widely used in stress analysis of anisotropic materials. ${ }^{27}$ In the present paper the polydomain material behavior is assumed to be given by weighted sum of both modes and a defect contribution:

$\mathrm{G}_{\text {texture }}^{\prime}=\varphi_{\text {splay }} \mathrm{G}_{\text {splay }}^{\prime}+\mathrm{G}_{\text {bend }}^{\prime} \varphi_{\text {bend }}+\mathrm{G}_{\text {defect }}^{\prime}$

where $\mathrm{G}_{\text {texture }}$ is the storage modulus of the textured sample, $G_{\text {bend }}$ is the storage modulus for the monodomain in bend distortion, $\mathrm{G}_{\text {splay }}$ is the storage modulus for the monodomain in splay distortion, $G_{\text {defect }}$ is the elasticity stored by the orientation defects (disclinations) that create the texture, and $\varphi$ is the volume fraction of each distortion mode. Equation 14 is derived using the uniform stress principle of textured materials, and it is reasonably convenient to represent the mesophase pitch in the multidistortion mode. In this study we assume that the mesophase pitch has an equal amount of domains that will be distorted in bend and splay modes, therefore $\varphi_{\text {splay }}=\varphi_{\text {bend }}=0.5$.

The elastic storage of orientational defects (disclination) of nematics liquid crystals is a well known phenomena. ${ }^{5,6,38,42-44}$ The amount of elastic storage depends on the domain size $(\mathrm{H})$, the defect charge $(\mathrm{S})$, and the temperature, as follows: ${ }^{5,6,38}$

$\mathrm{G}_{\text {defect }}^{\prime}=\mathrm{c} \frac{\mathrm{K}(\mathrm{T}) \mathrm{S}}{\mathrm{H}^{2}}$

where $\mathrm{c}$ is a constant, $\mathrm{K}(\mathrm{T})$ is the characteristic Frank elastic constant or average of splay, bend, and twist. In the present study we take into account the defect elastic storage for three temperatures, $\mathrm{T}_{1}<\mathrm{T}_{2}<\mathrm{T}_{3}$. As well known, $\mathrm{K}(\mathrm{T})$ is a decreasing function of increasing temperature, equation 15 predicts that $\mathrm{G}^{\prime}{ }_{\text {defect }}$ decreases with increasing temperature. No exact temperature is indicated in this paper because no comprehensive data exist for the temperature dependency of $\mathrm{K}$ for carbonaceous mesophases. The selected $\mathrm{K}$ values are equal to $10^{-7} \mathrm{~Pa}\left(\mathrm{~T}=\mathrm{T}_{3}\right), 10^{-6} \mathrm{~Pa}\left(\mathrm{~T}=\mathrm{T}_{2}\right)$, and $10^{-5} \mathrm{~Pa}$ $\left(\mathrm{T}=\mathrm{T}_{1}\right)$, respectively, which imply that domain size is in the micron range, as observed experimentally. ${ }^{44}$

Figure 7 shows the computed storage modulus $\left(\mathrm{G}_{\text {mix }}^{\prime}\right)$ as a function of frequency $(\omega(\mathrm{rad} / \mathrm{sec}))$ of a textured 
carbonaceous mesophase in the small frequency regime at three temperatures $\left(\mathrm{T}_{1}<\mathrm{T}_{2}<\mathrm{T}_{3}\right)$, computed using equation 14 . The figure shows a plateau in the terminal zone $(\omega<0.1)$, whose amplitude decreases with increasing temperature, in perfect agreement with Figure 3. The solid like behavior is due to the domain texture, whose elastic solid-like nature is due to the presence of orientational defects. ${ }^{44}$

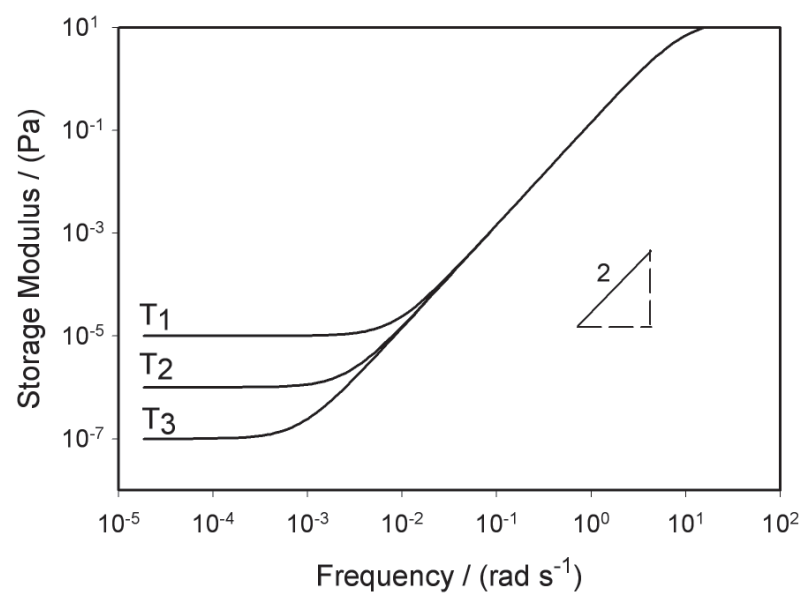

Figure 7. Computed storage modulus $\left(\mathrm{G}^{\prime}{ }_{\text {mix }}\right)$ for mesophase pitch as a function of the frequency $(\omega)$ for multi distortion mode and polydomain with elasticity stored in the defects $\left(\mathrm{G}_{\text {defect }}\right)$ and three temperatures $\left(\mathrm{T}_{1}<\mathrm{T}_{2}<\mathrm{T}_{3}\right)$.

\section{Conclusions}

This paper extends the theoretical methods used to describe the linear viscoelasticity of anisotropic textured carbonaceous mesophases. Previous models focused on single deformation modes in the absence of defects. It is well known that carbonaceous mesophases are textured materials, that when sheared store elasticity due to orientation gradients and orientational defects. A linear viscoelasticity model based on the constant stress principle used to described anisotropic textured materials is developed based on liquid crystal physics. The model predict that at low frequencies the loss modulus is insensitive to temperature, textures and deformation modes, since dissipative mechanisms are insensitive to the presence of defects. On the other hand, the model predicts that the storage modulus has a strong sensitivity to temperature, and texture. The solid like behavior observed in the terminal zone is attributed to topological defects. The model predictions are in excellent agreements with experiments. This work provides a new way to incorporate textural information into linear viscoelasticity and hence provides new tools to understand and use experimental linear viscoelastic data. As shown by Equation 15 the solid like behavior displayed by G' can easily be converted into a texture scale $(\mathrm{H})$ or into a Frank elastic constant.

\section{Acknowledgments}

This research was supported by a grant from Engineering Research Center program of National Science Foundation (USA) under award number EEC 9731680.

\section{References}

1. Singer, L. S.; Fuel 1981, 60, 839.

2. Marsh, H.; Latham, C. S.; ACS Symposium Series 1986, 303, 1.

3. Edie, D. D.; Diefendorf, R. J. In Carbon-Carbon Materials and Composites; Buckley, J. D; Edie, D. D., eds.; Noyes Publications, 1993, p. 19.

4. Edie, D. D. In Design and Control of Structure of Advanced Carbon Materials for Enhanced Performance; Rand, B.; Appleyard, S. P.; Yardim, M. F., eds.; Kluwer Academic Publishers: Netherlands, 2001, p. 163.

5. Chandrasekhar, F. R. S.; Liquid Crystals, $2^{\text {nd }}$ ed., University Press: Cambridge, 1992.

6. de Gennes, P. G.; Prost, J.; The Physics of Liquid Crystals, $2^{\text {nd }}$ ed., Oxford University Press: London, 1993.

7. Rey, A. D.; Denn, M. M.; Annu. Rev. Fluid Mech. 2002, 34, 233.

8. Nazem, F. F.; Fuel 1980, 59, 851.

9. Sakai, M.; Inagaki, M.; Carbon 1981, 19, 37.

10. Nazem, F. F.; Carbon 1982, 20, 345.

11. Nazem, F. F.; Lewis I. C.; Mol. Cryst. Liq. Cryst. 1986, 139, 195.

12. Oh, K. H; Ryu, S. K.; Rhee, B. S.; Korean J. Chem. Eng. 1986, 3, 93.

13. Rand, B.; Fuel 1987, 66, 1491.

14. Fathollahi, B.; White, J. L.; J. Rheol. 1994, 38, 1591.

15. Fleurot O.; Edie, D. D.; J. Rheol. 1998, 42, 781.

16. Cato, A. D.; Edie, D. D.; Carbon 2003, 41, 1411.

17. Cato, A. D.; Edie, D. D.; Harrison, G. M.; J. Rheol. 2005, 49, 161.

18. Grecov, D.; Rey, A. D.; Mol. Cryst. Liq. Cryst. 2003, 391, 57.

19. Grecov, D.; Rey, A. D.; J. Rheol. 2005, 49, 175.

20. de Andrade Lima, L. R. P.; Rey, A. D.; J. Non-Newton. Fluid Mech. 2003, 110, 103.

21. de Andrade Lima, L. R. P.; Rey, A. D.; J. Rheol. 2003, 47, 1261.

22. de Andrade Lima, L. R. P.; Rey, A. D.; Mater. Res. 2003, 6, 285.

23. de Andrade Lima, L. R. P.; Rey, A. D.; Carbon 2004, 42, 1263.

24. Sakai, M.; Sato, Y.; Inagaki, M.; Carbon'90: Extended Abstracts and Program - International Carbon Conference, Paris, 1990, p. 298.

25. Hara, R.; Carbon'90: Extended Abstracts and Program International Carbon Conference, Paris, 1990, p. 290. 
26. Hara, R.; Mitsubishi Kasei R\&D Review 1992, 6, 19.

27. Hara, R.; Nihon Reoroji Gakkaishi 1993, 21, 74.

28. Turpin, M.; Cheung, T.; Rand, B.; Carbon 1994, 32, 225.

29. Cheung, T.; Turpin, M.; Rand, B.; Carbon 1996, 34, 265.

30. Wu, X. X.; Wang, C. Y.; Guo, C. T.; Carbon 1998, 36, 1291.

31. de Andrade Lima, L. R. P.; Rey, A. D.; Chem. Eng. Sci. 2004, 59, 3891.

32. Hurt, R.; Krammer, G.; Crawford, G.; Jian, K. Q.; Rulison, C.; Chem. Mater. 2002, 14, 4558.

33. Jian, K.; Shim, H-S.; Tuhs-Dubrow, D.; Bernstein, S.; Woodward, C.; Pfeffer, M.; Steingart, D.; Gournay, T.; Sachsmann, S.; Crawford, G. P.; Hurt, R. H.; Carbon 2003, 41, 2073.

34. de Andrade Lima, L. R. P.; Rey, A.D.; Phys. Rev. E: Stat., Nonlinear, Soft Matter Phys. 2004, 70, 011701-1.

35. de Andrade Lima, L. R. P.; Rey, A.D.; J. Rheol. 2004, 48, 1067.
36. de Andrade Lima, L. R. P.; Rey, A.D.; Rheol. Acta 2006, in press.

37. Hyer, M. W.; Stress Analysis of Fiber-Reinforced Composite Materials, WCB/McGraw-Hill: New York 1998.

38. Chandrasekhar, S.; Ranganath, G. S.; Adv. Phys. 1986, 35, 507.

39. Rey, A. D.; Rheol. Acta 1995, 34, 461.

40. Rey, A. D.; Mol. Cryst. Liq. Cryst. 1996, 281, 155.

41. Rey, A. D.; Liq. Cryst. 1996, 20, 147.

42. Currie, P. K; Leslie, F. M.; Arch. Ration. Mech. Anal. 1984, 87, 35.

43. Yada, M.; Yamamoto, J.; Yokoyama, H.; Langmuir 2003, 19, 3650.

44. Zimmer, J. E.; White, J. L.; Adv. Liq. Cryst. 1982, 5, 157.

Received: January 22, 2006

Published on the web: June 29, 2006 